\title{
Uma tentativa de afastar as sombras: A Costa dos Murmúrios, de Lídia Jorge
}

\author{
Isa Lopes Coelho \\ (Universidade Federal Fluminense)
}

\section{RESUMO}

O romance $A$ costa dos murmúrios de Lídia Jorge desmistifica o discurso da história oficial e revela a desintegração da identidade nacional portuguesa. Num primeiro momento do romance, o discurso mítico de supremacia do 'grande império Português' é reduplicado nas vozes harmônicas 'da verdade única' das 'Evitas', estas 'rendilheiras do Stella', Penélopes à espera dos seus 'heróis', que se fazem ouvir no relato de "Os Gafanhotos". Entretanto, logo depois, testemunhamos a desconstrução deste discurso representado em "Os Gafanhotos" e a construção de uma verdade vacilante que se equilibra na precariedade dos murmúrios das memórias e nos mantém conscientes da fragilidade destas lembranças enquanto sujeitas a um filtro seletivo e parcial.

PALAVRAS-CHAVE: autoridade; memória; conto

\section{ABSTRACT}

The novel $A$ costa dos murmúrios de Lídia Jorge dismystifies the discourse of the official history and unveils the desintegration of the Portuguese national identity. In a first moment of this novel, the mythical discourse of the supremacy of the 'great Portuguese Empire' is redoubled in the harmonic voices of 'the univocal historic truth' of the 'Evitas', those 'rendilheiras do Stella', Penelopes awaiting their 'heroes', who have a voice in the account of "Os Gafanhotos". However, soon afterwards, we witness the deconstruction of this discourse represented in "Os Gafanhotos" and the construction of a vacillant truth that finds its balance in the precariousness of the murmuring of the memories and keeps us aware of the fragility of this recollection as it is subject to a selective and partial filter.

KEYWORDS: authority; memory; tale 
"A teoria tem uma força vital que ultrapassa a vida. A teoria e o conto."

Lídia Jorge (1988, p. 258)

O romance $A$ costa dos murmúrios, de Lídia Jorge, tem sido objeto de inúmeros estudos literários que, na sua grande maioria, focalizam os aspectos formais da narrativa, além de questões inerentes ao nosso tempo, inserindo-o no que Linda Hutcheon denomina de metaficção historiográfica. É um romance que, ainda segundo Hutcheon, pode ser definido como aquele em que a fronteira entre história e ficção encontra-se empalidecida na medida em que o texto se mostra "deliberadamente fictício e, apesar disso, ao mesmo tempo, inegavelmente histórico". (HUTCHEON, 1991, p. 184). Neste breve estudo, temos por objetivo tecer algumas considerações adicionais dentro desse mesmo viés.

O romance de Lídia Jorge se revela metaficcional ao enfatizar repetidamente seu caráter de construto e, enquanto narra os fatos, discutir seu processo de criação, levantando questões sobre a sempre complexa relação entre ficção e realidade. A história se passa em Beira, Moçambique, e tem seu discurso ficcional autenticado através de referências a acontecimentos localizados historicamente nos primeiros quatro anos da década de 70 , período que antecedeu o final das guerras coloniais: a operação Nó Górdio, no território maconde de Cabo Delgado, comandada pelo General Kaúlza de Arriaga, 'o general' do texto, e o massacre de Wiryiamu, evidenciado na narrativa pelas fotos que Helena mostra a Evita e pelo relato da 'limpeza' apresentado pelo alferes Góis. Todavia, a narrativa de Lídia Jorge subverte a narrativa tradicional da guerra ao ignorar qualquer descrição direta das ações bélicas enquanto teoriza e re-inventa o ato de escrever sobre a guerra.

O romance divide-se em duas narrativas separadas dos mesmos fatos, mas é só ao final da leitura de ambas as partes que se consegue apreender a obra em toda a sua densidade. A primeira narrativa, intitulada "Os gafanhotos", cuja ação se passa quase que totalmente no terraço do hotel Stella Maris, constitui-se de um breve relato que, em terceira pessoa, narra a comemoração do casamento entre o alferes Luís Alex e Evita, além de trazer à baila alguns acontecimentos paralelos. Suas personagens são oficiais portugueses e suas famílias, que, na sua maioria, estão hospedados nesse hotel. Fica bem clara a ênfase dada ao papel da mulher como moldura nesse contexto da guerra, entretanto - com exceção de Evita e Helena, a mulher do capitão -, as mulheres não têm nomes próprios, sendo denominadas de "as mulheres dos oficiais" ou "as rendilheiras do Stella", numa clara referência à Penélope. Desempenham o papel que tradicionalmente, em sociedades patriarcais, se espera das mulheres patriotas no período de guerra: aceitam com submissão a agressividade dos maridos, reduplicam seus discursos, fazem tudo para justificar seus atos violentos e desumanos e se recusam a entender aquilo que possa ser comprometedor. As mais novas, com seus cabelos longos passados a ferro, desesperam-se quando se veem diante de situações insustentáveis, "sentiam-se abatidas como as frutas podres, porque não havia quem culpar"; as mais velhas, de cabelo em forma de colmeia, "suportavam melhor porque muita morte inútil já tinha ficado por explicar”. (JORGE, 1988, p. 116). A professora Margarida Calafate Ribeiro desenvolveu um cuidadoso estudo sobre o papel da mulher portuguesa durante o período da Guerra Colonial na África e aponta para um fato inédito que ocorreu naquela ocasião: 
[A] ida de mulheres acompanhando os maridos em missão militar na África. Aproximando assim a chamada 'frente interna' da frente de guerra, proporcionou-se uma certa estabilidade social dentro de um quadro de inevitável mudança. Paradoxalmente, criaram-se também, a prazo, as condições para a mudança, na medida em que essas mulheres seriam também testemunhas e, de alguma forma, cúmplices de um mundo de guerra, aparentemente reservado aos homens. (RIBEIRO, 2004, p. 15).

Entendemos que, em $A$ costa dos murmúrios, as 'rendilheiras do Stella' emergem da obra como cúmplices da violência masculina, ainda que, na maioria das vezes, seja uma cumplicidade que se dá pelo silêncio.

Essa primeira parte do romance, cujo ponto de vista predominante é o do opressor, parece alimentar a 'verdade única' por tanto tempo veiculada pela história oficial, que sustentava e era sustentada pelo imaginário nacional, ao nos dar uma imagem espetacular, quase mágica, na sua harmonia e encantamento, de um episódio tão trágico da guerra colonial. Uma leitura menos atenta deste relato cairia na armadilha de apenas registrar o clima de festa que reina neste suposto oásis de paz e encanto, onde casais riem e dançam descontraidamente; nada que lembrasse que estavam em pleno processo da guerra, pois "ainda era muito cedo para se falar em guerra, que, aliás, não era guerra, mas apenas uma rebelião de selvagens... Era muito cedo para se falar em Império...”. (JORGE, 1988, p. 13).

A paz desse oásis não é maculada nem mesmo quando tomam conhecimento de que uma infinidade de pretos apareceram mortos na praia e estão sendo recolhidos por dumpers de lixo. A grande comoção se dá geográfica e emocionalmente fora do hotel. Para os oficiais portugueses e suas esposas, tudo não passa do grande espetáculo duma "noite secreta e memorável" (JORGE, 1988, p.18) a que assistem, "dos seus camarotes", munidos de binóculos para nada perder:

Afinal, durante a noite, haviam pressentido algo de deslumbrante, mas exaustos do cortejo, tinham mergulhado num sono estúpido sem darem importância às corridas que passavam sob as janelas do hotel Stella Maris. Tinha sido pena! Aliás, por que razão haviam sido céleres em recolher os corpos? Essa era uma pergunta colectiva mas que só alguns formulavam. (JORGE, 1988, p. 20).

Os portugueses não têm dificuldade em encontrar explicações para o ocorrido, ainda que se tratassem de "estivadores, homens de potentes músculos, bons nadadores”. (JORGE, 1988p. 19). O major acredita nas matanças sazonais e crê que tenham se matado à catanada e foram-se atirando ao mar ou talvez, num gesto nobre e por se saberem vencidos, suicidaram-se coletivamente. Tudo é explicado com muita 'naturalidade'. Em um curto parágrafo a palavra 'naturalmente' é repetida oito vezes. E uma imensa ternura se instaura entre os casais, "como se depreende, a ternura e o entendimento eram o contraponto daquele arrebatador espetáculo, cujo auge, acontecido durante a noite, era preciso imaginar. A imaginação despertava a ternura". (JORGE, 1988, p. 21). Mas quando ficam sabendo que, na verdade, os pretos foram os responsáveis por seu próprio envenenamento, eles ficam chocados 
com tanta 'estupidez' e tudo perde a graça e a beleza. Não obstante, o essencial era acreditar que eles não tinham nada a ver com a mortandade dos pretos e poder "regressar todos ao terraço, pedir ao Gerente que mandasse servir lá em cima o almoço, e se possível o jantar, para não perderem a cena de barbárie que estava afinal ocorrendo entre o Chiveve e o mar". (JORGE, 1988, p. 24). O importante era manter nas trevas tudo que pudesse abalar a supremacia do 'grande império português'. As luzes? "E para quê acendê-las? Devia-se deixar as sombras ocultarem as árvores pelas suas próprias sombras...". (JORGE, 1988, p. 31).

Essa imagem idealizada da guerra e dos seus heróis não podia ser manchada: Percebia-se que ninguém falava em guerra com seriedade. O que havia ao Norte era uma revolta e a resposta que se dava era a contra revolta. Ou menos do que isso - o que havia era banditismo, e a repressão do banditismo chamava-se contra-subversão. Não guerra. (JORGE, 1988, p. 74).

Não que a palavra 'guerra' não fosse usada, muito pelo contrário, era citada todo o tempo, para se referir a qualquer ação, desde que não fosse para se referir ao conflito armado: "A desvalorização da palavra correspondia a uma atitude mental extremamente sábia e de intenso disfarce”. (JORGE, 1988, p. 74). Oficialmente, não estavam em guerra. Assumir sua existência era desmistificar os fundamentos identitários da Grande Nação Portuguesa, nos quais metrópole e colônias formariam uma só Nação. Não se assumia, sobretudo, qualquer ligação entre o desequilíbrio emocional que afligia alguns oficiais e o genocídio do qual participavam. E, ao final do relato, todos, inclusive Evita, atribuem o suicídio do noivo ao excesso de harmonia, felicidade e beleza e concluem que "as guerras eram necessárias para equilibrar o excesso de energia que transbordava da alma". (JORGE, 1988, p. 38).

Entretanto, uma leitura mais cuidadosa de "Os Gafanhotos", que transponha a densa ironia e paródia do discurso do seu narrador, vai revelar que esse relato, à semelhança de um lead jornalístico, já traz em si, veladas sob uma linguagem metafórica e codificada, as questões que serão mais explicitamente tratadas na segunda parte do romance. Afinal Álvaro Sabino, o autor de "Os Gafanhotos" é o mesmo jornalista que escrevia as colunas das quintas-feiras no Hinterland e que confessa a Evita que "Nos regimes como este, mesmo caindo aos pedaços, não se escreve, cifra-se. Não se lê, decifrase". (JORGE, 1988, p. 147).

Ainda nesse primeiro momento do romance, há indícios velados/revelados da falência do grande império português e do sistema colonial. Seus oficiais, esses grandes heróis portugueses, tão exaltados pela história oficial, começam a ser desmascarados no relato de "Os Gafanhotos", quando se inicia uma tentativa de afastar as sombras, de iluminar as trevas que durante longos anos povoaram a consciência portuguesa.A falência do 'discurso oficial' se revela até mesmo por aqueles que aparentemente o reproduzem. Um exemplo dos mais marcantes se dá quando alguém pergunta como resolver a situação da colônia e a solução vem do General, "detentor da esperteza necessária" - a esterilização compulsiva ou persuasiva, castração voluntária em troca da qual se ofereceria um rádio aos cafres, ou, segundo outra ideia do General, "bastaria apenas anular os serviços de assepsia, para a natalidade inflectir como uma linha que some!". (JORGE, 1988, p. 25). Esse mesmo general, na segunda parte do romance, ao voltar de Cabo Delgado, faz um discurso celebrando as recentes grandes vitórias, repleto de alusão a um 
passado glorioso totalmente destoante da realidade, e que é desmentido pelo próprio noivo, como tendo sido "uma grandessíssima merda". (JORGE, 1988, p. 237). Em outro momento, o paraquedista lesionado - não há como desconhecer a ironia dos epítetos - diz que "Moçambique está para a África Austral como a Península Ibérica está para a Europa - estão ambas como a bainha está para as calças" e, perguntado sobre de quem é a culpa, responde numa das falas mais cínicas de todo o romance:

Deles, da qualidade dos blacks que nos calharam em sorte! [...] Se tivéssemos tido uns blacks fortes, tesos, aguerridos, nós, os colonizadores, teríamos saído da nossa fraqueza. Eles é que são os culpados, e se lhes parecemos fortes é porque eles mesmos são extremamente fracos. Só temos de os recriminar [...]. (JORGE, 1988, p. 28).

Contudo, ao ver as fotografias guardadas em segredo na casa do capitão e ler os relatos dos combatentes, Evita toma conhecimento de uma 'outra guerra', o avesso da dramatizada no Stella Maris, "o grande envenenamento que cai sem saber donde, sobre todas as coisas" JORGE, 1988, p. 126) e disseminou a destruição: "eu me apaixonei por um rapaz inquieto à procura de uma harmonia matemática e hoje estou esperando por um homem que degola gente e espeta num pau" (JORGE, 1988, p. 167). E vinte anos depois, não mais Evita, mas Eva, aquela que foi maculada porque provou do fruto do conhecimento, e que já recebera "a forquilha do garfo dentado" de "um demônio metafísico, reluzente, encarnado" e tinha avaliado o "quanto a árvore da sabedoria era do demônio, e a erva da inocência pertencia a Deus e seus correligionários" (JORGE, 1988, p. 220), parte para anular "aquilo que termina tão bem, tão oficialmente", aquilo que "está tão escondido", "tudo [aquilo que] termina tão conforme as versões suaves que foram feitas". (JORGE, 1988, p. 252-253).

Margarida Ribeiro reconhece que nem todas as mulheres que acompanharam seus maridos cumpriram com a sua função de mantenedoras da família, assim como estabelecida em termos tradicionais, corporativos e ideológicos pelo regime:

Acredito que muitas das mulheres que foram para África, acompanhando os maridos na guerra, colaboraram, voluntária ou involuntariamente, consciente ou inconscientemente, para a produção do disfarce da guerra sob uma imagem de normalidade que o regime queria projectar. No entanto, e como é bem visível nos depoimentos que podemos obter destas mulheres e na literatura que ficcionalmente as refere, havia outras mulheres portuguesas que parecia não encaixarem na moldura requerida e esperada. (RIBEIRO, 2004, p. 23).

Eva fazia parte desse segundo grupo ao qual Ribeiro se refere. Ela é o elemento estranho na comunidade das 'mulheres do Stella'. Sendo assim, na segunda parte do romance, como leitora, critica e teórica, Eva desenvolve um processo de desconstrução e reconstrução do relato ao confrontar a versão dos fatos que o jornalista Álvaro Sabino apresentou em "Os Gafanhotos” com a sua própria versão de protagonista da estória, enquanto Evita. Os temas anteriormente introduzidos no relato são aí aprofundados, mas jamais fechados. Numa brilhante conferência no Real Gabinete Português, a 
Professora Isabel Pires de Lima nos falou de como os romances de Lídia Jorge se valem de uma memória que não memorializa, que se mantém oscilante. Essa indeterminação se confunde com uma reflexão metanarrativa que põe em cheque a oposição entre ficção e realidade.

Eva aprova o relato do jornalista e considera que "tudo é exato e verdadeiro, sobretudo em matéria de cheiro e de som... Além disso, o que pretendeu clarificar clarifica, e o que pretendeu esconder ficou imerso". (JORGE, 1988, p. 41). A ironia que está por trás desta afirmação nos leva a crer que nada, além do cheiro e do som, é verdadeiro no relato e assim introduz toda uma discussão sobre a tensão entre a verdade e o real: "definitivamente, a verdade não é o real, ainda que gêmeos, e n"Os Gafanhotos' só a verdade interessa" (JORGE, 1988, p. 85), porque para que a verdade única, oficial, inquestionável se estabeleça, é preciso que ela seja " unida e infragmentada", enquanto o real " tem de ser porque senão explodiria - disperso, irrelevante, escorregando, como sabe, literalmente para lugar nenhum". (JORGE, 1988, p. 85).

Eva aconselha o jornalista a não se preocupar "com a verdade que não se reconstitui, nem com a verossimilhança que é uma ilusão dos sentidos" (JORGE, 1988, p. 42) e, ao recordar os fatos que ela própria viveu, faz uma seleção de acordo com o que ela chama de 'correspondência'. Até mesmo as personagens estão submetidas a essas 'correspondências':

Não, não vou dizer que as figuras estão erradas, e que é indiferente que estejam erradas, de modo nenhum. Tudo está certo e tudo corresponde. Veja por exemplo o major. Esse magnífico major. Está tão conforme que eu nunca o vi, e o reconheço a partir do seu relato como se fosse meu pai. Reconheço-o obviamente porque os dentes dele estavam numa outra boca, o pingalim numa outra mão, os cabelos oleados andavam despegados do pingalim e dos dentes, numa outra pessoa... Ah, como admiro essa figura que encontrei espalhada por várias! ... claro que não foi assim, mas a correspondência é perfeita. (JORGE, 1988, p. 43).

E quando se desconstrói essa "narrativa onde tudo termina tão bem, tão oficialmente" (JORGE, 1988, p. 252), um outro traço metaficcional do romance, já salientado por estudiosos da obra de Lídia Jorge, se revela - a crítica da História dentro da própria estória. Vamos acompanhar todo um processo de desmistificação daquilo que por muito tempo foi considerado como uma verdade incontestável, constatamos que a ironia é usada com a função de subversão do discurso vigente e, então, o conceito de história única é questionado, surgindo verdades plurais, frutos de olhares múltiplos.

A Verdade e a História são apenas 'coincidências' que oferecem possíveis versões e o caráter autorreflexivo da ficção fica assim evidenciado. Se nada é necessariamente endossado por uma realidade pré-existente e "tudo tem uma ligação com tudo, e o que não tem não é relevante" (JORGE, 1988, p. 201), ficção e realidade só se constróem na e pela linguagem e a distinção entre elas fica, assim, bastante tênue.

Eva assume que "a verdade é que me lembro de fragmentos. E para quê mais?" ou que "me lembro imperfeitamente, o que não deve ter nenhum significado secundário". (JORGE, 1988, p. 127). A narrativa da segunda parte do romance, sujeita às lembranças de Eva, apresenta-se caótica, repleta de lacunas que assim permanecem, testemunhando aquela parte do passado que, 
voluntária ou involuntariamente, não se consegue alcançar até porque só existe enquanto objeto incompleto e fragmentado, e que estaria mais próximo do esquecimento do que da reminiscência. Por conseguinte, não há intenção de dar um caráter autoritário ao discurso de Eva/Evita ou mesmo ao do jornalista, nem sequer de apresentá-los como substitutos do discurso da História: "Entre o bem e o mal uma mortalha de papel de seda (...) 'Sendo assim, tanto faz - tudo é idêntico a tudo' pensou transitoriamente" (JORGE, 1988, p. 141) (grifo nosso). A modalização reforça a indefinição do discurso. A própria Eva diz que "memória é uma fraude para iludir o olvido cor de pó". (JORGE, 1988, p. 73).

Na conferência à qual nos referimos acima, a Professora Isabel Pires de Lima sublinhou que as obras de Lídia Jorge tematizam questões da identidade nacional assim como de identidades individuais; dando mais ênfase, ora a uma, ora a outra.

Já em sua primeira parte, $A$ costa dos murmúrios evidencia a impossibilidade de divorciar o particular e o pessoal do público. Enquanto estudantes, Evita e Luís encontravam-se numa pastelaria sugestivamente chamada 'Ideal', onde o noivo discursava sobre seus projetos acadêmicos. Os 'ideais' do noivo, porém, se desfazem, da mesma forma que os 'ideais' do Império Português, ante as barbáries da guerra colonial.

Fica bem claro que, para Eva Lopo, o pessoal e o nacional se confundem.Ao tomar conhecimento das atrocidades praticadas pelos oficiais portugueses, ela procura o jornalista para denunciá-los e tornar públicos esses crimes que, até então, mantinham-se ocultados nas versões oficiais: "vejo sombras" (JORGE, 1988, p. 136). Porém, esses fantasmas estão na história da nação, mas estão também na sua própria estória. A modificação que se opera no noivo e que transforma o antigo estudante de matemática num sádico e desumano decepador de cabeças é, sobretudo, a causa de sua melancolia, de sua perda de referência e da fragmentação do seu discurso e de sua subjetividade: "o que tentava era achar finalmente o momento, o brilho, a palavra que desencadeava na pessoa o gosto de degolar", ainda que soubesse que "era sem dúvida uma enorme ambição". (JORGE, 1988, p. 139).

Durante todas as suas lembranças, Eva tem uma atitude ambígua em relação à Evita, como bem ressalta Paulo de Medeiros no seu artigo "Memória Infinita": "Eva Lopo rejeita, ao mesmo tempo em que reconhece, a sua identidade prévia. A necessidade de isolar Evita como um outro eu, restrito a um passado e a um lugar específicos pode ser encarada como uma estratégia imprescindível à sua sobrevivência". (MEDEIROS, 1999, p. 74). A tal ponto, que a personagem considera: "Vim enganada parar naquela costa - o que me chamou, ou me empurrou, quis que sofresse a desilusão sobre todas as coisas daquela costa”. (JORGE, 1988, p. 124).

Para tentar reconstruir sua identidade, Eva precisa entender como se passou essa transformação no noivo, quando isso começou e o que a motivou. Ela acredita que tudo se dá devido à perda de memória: "Mas agora parecia haver perdido a memória de tudo isso, ali no pequeno quarto de África... Então se fôssemos esquecendo do que desejávamos descobrir, e depois de como nos chamávamos, e a seguir de que país éramos...". (JORGE, 1988, p. 47). E confessa sua preocupação para o jornalista: "se nunca mais evocar esta lembrança à luz duma lâmpada ocasional como a sua, o Stella inteiro... acabará aqui". (JORGE, 1988, p. 209). Ainda no relato, Evita reconhece que "se ninguém fotografou nem escreveu, o que aconteceu durante a noite acabou com a madrugada - não chegou a existir".(JORGE, 1988, p. 21); que "é impossível suster uma ruína só com a vontade" (JORGE, 1988, p. 108); que 
"de nada vale querer que existam nos escombros os fantasmas".(JORGE, 1988, p. 111).

Ela não confia na memória, "A pouco e pouco as palavras isolam-se dos objetos que designam, depois das palavras só se depreendem sons, e dos sons restam só os murmúrios, o derradeiro estádio antes do apagamento". (JORGE, 1988, p. 259). Entretanto, confia na ficção, naquilo que não foi, mas poderia ter sido - "A teoria tem uma força vital que ultrapassa a vida. A teoria e o conto" (JORGE, 1988, p. 258) -, e pede ao jornalista: "Por favor, evite as sombras. Tem-se feito um esforço enorme ao longo destes anos para que todos nós o tenhamos esquecido. Não se deve deixar passar para o futuro nem a sombra duma cópia, nem a ponta duma sombra”. (JORGE, 1988, p.136).

Cada vez que nós acrescentamos a nossa voz às vozes de Eva Lopo e Álvaro Sabino, estamos contribuindo na tentativa de afastar as sombras que querem fazer crer que massacres como o de Wiryiamu não aconteceram.

A grande sabedoria desse texto de Lídia Jorge se encontra, exatamente, não no uso magnífico que realiza do romance histórico, nem no ato metaficcional que pratica com muita segurança e de forma legível. Seu texto avulta pela invulgar forma de lidar com a memória: nem sistema baseado na factualidade histórica, nem negação dessa mesma existência 'fora do texto', a memória é, no entanto, a instância que dinamiza o modo de ser do 'fato em ficção', 'do como se' ficcional que redimensiona o vivido e o transforma na experiência crítica e irônica que redobra, na literatura, o olhar arguto para uma realidade de outra forma apenas registrável. Aqui, nesse texto de Lídia Jorge, a memória ficcional transforma os murmúrios do império e as dores do oprimido em alegorias de um tempo que, colhido na dobra da ficção que o faz de verdade 'viver', faz falar as ruínas de um império cuja identidade e autoridade se esfacelaram na corrosão que praticou.

\section{REFERÊNCIAS BIBLIOGRÁFICAS}

HUTCHEN, Linda. Poética do pós-modernismo. Rio de Janeiro: Imago, 1991.

JORGE, Lídia. A costa dos murmúrios. Lisboa: Dom Quixote, 1988.

MEDEIROS, Paulo de. Memória Infinita. Portuguese Literary \& Cultural Studies, Boston, n.3, p. 61-77, Spring 1999.

RIBEIRO, Margarida Calafate. África no Feminino: As Mulheres Portuguesas e a Guerra Colonial. Revista Crítica de Ciências Sociais, Coimbra, nº 68, p.729, Abril 2004. 